Global Business Research Congress, May 30-31, 2019, Istanbul, Turkey.

\title{
FRAUD DETECTION IN INTERNAL AUDIT: CASE STUDY
}

\section{DOI: 10.17261/Pressacademia.2019.1064 \\ PAP-V.9-2019(11)-p.54-57}

\section{Salih Kayikcioglu ${ }^{1}$, Suat Teker ${ }^{2}$}

${ }^{1}$ Işık University, Graduate School of Social Sciences, Maslak Campus, Sariyer, İstanbul, Turkey. salih.kayikcioglu@isikun.edu.tr, 0000-0003-3187-5785

${ }^{2}$ Işık University, Maslak Campus, Sariyer, Istanbul, Turkey.

suat.teker@isikun.edu.tr, ORCID: 0000-0002-7981-3121

To cite this document

Kayikcioglu, S., Teker, S., (2019). Fraud detection in internal audit: case study. PressAcademia Procedia (PAP), V.9, p.54-57

Permemant link to this document: http://doi.org/10.17261/Pressacademia.2019.1064

Copyright: Published by PressAcademia and limited licenced re-use rights only.

\section{ABSTRACT}

Purpose- This research is carried out to reveal the effect of internal control system in preventing fraud that may occur in the enterprises. In this context, the study conducts to determine the relationship between internal control and fraud prevention.

Methodology- In order to achieve this aim, a real case is investigated by examining the elements of fraud and errors based on the environment where fraud is detected.

Findings- Initially, the fraudulent situation is observed. Later, the relationship in between the fraud and fraudulent situation is detected over an internal audit process.

Conclusion- All phases of a classical triangle of fraud is clearly observed in this case.

Keywords: Fraud, mistaken, triangle of fraud, internal audit

JEL Codes: M40, M41, M42

\section{IÇ DENETIMDE HILE TESPITi: ÖRNEK OLAY ÇALIŞMASI}

\section{ÖZET}

Amaç- Bu araştırma, işletmelerinde meydana gelebilecek hileleri önlemede iç kontrol sisteminin etkisini ortaya koymak amacıyla yapılmıştır. Bu bağlamda, iç kontrolün hileleri önleme arasında nasıl bir ilişki olduğunu tespit etmeye çalışılmıştır.

Yöntem- Bu amaca ulaşmak için, hile ve hata unsurlarının dikkatlice değerlendirmesi yapılıp, hilenin oluşma şartlarından yola çıkılarak, bir vak'a incelenmesi yapılmıştır.

Bulgular- Öncelikle, hileli bir durumun ortaya çıktığı tespit edilmiştir. Devamında ise, iç denetçi tarafından hile olması ve bu hilenin oluşması için gerekli şartlar arası ilişki gözlenmiştir.

Sonuç- Hilenin oluşması için gerekli ve klasik olarak bilinen hile üçgeninin tüm evreleri bu örnek olayda gözlenmiştir

Anahtar Kelimeler: Hile, hata, hile üçgeni, iç denetim.

JEL Kodları: M40, M41, M42

\section{GiRiş}

İşletmelerin geleceğe güvenle bakabilmelerinde iç kurumsal yönetim ve denetim sisteminin etkinliği büyük önem taşımaktadır. İç denetim sisteminin etkinliği işletmeler açsından büyük zararlara sebep olan hile ve yolsuzlukların önlenmesinde de büyük önem arz etmektedir. Bu çalışma işletmelere ve ülke ekonomisine olumsuz etkisi olan iç kontrol sistemindeki sorunlardan kaynaklanan hile ve yolsuzlukların önlenmesi konusunda yapılacak aştırmalara kaynak sağlaması açısından önem taşımaktadır.

$\mathrm{Bu}$ araştırma, işletmelerinde meydana gelebilecek hileleri önlemede iç denetim sisteminin etkisini ortaya koymak amacıyla yapılmıştır. Bu bağlamda, iç denetimin hileleri önleme arasında nasıl bir ilişki olduğunu tespit etmeye çalışılmıştır. 


\section{LITERATÜR INCELEMES}

\subsection{Hata}

Muhasebe bilimi için hata, finansal tablolarda ve muhasebe kayıtlarında yapılan matematiksel yanlışlıklar ya da muhasebe ilkelerinin uygulanmasında gözden kaçma ve gerçek verilerin istem dışı yanlış beyanlarıdır. Bir işletmenin ekonomik açıdan tanınması veya değerlendirilmesi muhasebe raporları esas alınarak yapılmaktadır. Bu anlamda, finansal tablolarda ya da muhasebe kayıtlarında meydana gelebilecek hatalar yanlış değerlendirmelere sebep olabilmektedir. (Ertürk, 2010: 3-4)

\subsection{Hile}

Herhangi bir şeyi sahibinden yasal olmayan şekilde almanın iki yolu bulunmaktadır. Birincisi fiziksel güç kullanmak ikincisi ise hile yapmaktır. Birinci yol olan fiziksel kuvvet, bir başkasına ait olan herhangi bir şeyi soygun yapmak olarak tanımlanmaktadır ve soygunlar genellikle şiddet içermektedir. Hile ise; başkalarını aldatmak, rüşvet, hırsızıı, sahtecilik, varlıkları kötüye kullanma, gerçekleri gizleme gibi anlamları ifade etmektedir. (Özkul ve Özdemir, 2010: 8)iş̧letme içinde veya dışında bulunan kişiler tarafından varlıkların zimmete geçirilmesi veya başka yararlar sağlamak için işletmenin finansal tablolarında ya da diğer kayıtlarında kasıtlı olarak yapılan zararlardır. (Terzi, 2012: 26)

Hile; gerçekleri saptırarak diğerleri üzerinden avantaj sağlamak için, bir kişi tarafından başvurulan ve insanın yaratıcılığı ile tasarlayabileceği her türlü muhtelif araçları kapsayan genel bir terimdir. Diğerlerini aldatmaya yönelik şaşırtmaca, hilekârlık, kurnazlık ve adil olmayan yöntemler içermesi nedeniyle hileyi tanımlarken kesin ve değişmez bir kurala dayalı genel bir ifade belirlenemez. Dolayısıyla hileyi tanımlarken bahsedilecek tek sınır insanın hilekârlığının/üçkâğıtçılığının sınırlarıdır. Hile, yapılan hatalardan farklıdır. Örneğin; işletme çalışanı finansal tablolara yanlış numara girerse bunu hata olarak adlandırabiliriz. Çünkü yapılan işlem kasıtlı veya avantaj elde etmek için yapılmamıştır. Ancak finansal tablolara girilen rakamların yatırımcıları kandırmak amacı gütmesi hile eylemini gösteren örneklerden bir tanesidir. Hile eyleminin ortaya çıkarılması, yapılan bir hata işleminin ortaya çıkarılmasından daha güç ve çok zaman almaktadır. Çünkü hile eylemini yapan kişi yaptığı eylemi hem kasıtlı hem de gizli olarak yapmaktadır. (Akdemir, 2010: 32-33)

\section{3. İç Kontrol}

İşletme terimi olarak kontrol, asıl amaçlar gerçekleştirildiği ve bu amaçları gerçekleştirme yolunda sorunlarla karşılaşıldığında, bu sorunları çözmek için önlemlerin alındığından emin olunması olarak ifade edilebilir (Kulak, 2009: 6). İç kontrolün ise değişik tanımları yapılabilir. Meslek gruplarına göre farklılık gösterebilir, muhasebe ile ilgilenenler, denetçiler, kanun yapıcılar, kendilerine göre birer tanım çıkarabilirler. Farklı meslek örgütlerinde tarihi süreç kapsamında farklı tanımlar yapılmıştır. İlk zamanlar işletme dahilinde çalışanların muhasebe işlemlerinde yaptığı hata ve hileleri tespit etmek, açığa çıkarmak ve bundan doğacak zararların önüne geçmek için kullanılan sistem, ilerleyen zamanlarda ise işletmenin kontrolünün sağlandığı vazgeçilmez bir yapı haline gelmiştir. Yapılan işlerin daha kısa sürede, düzen içinde ve daha fazla verim alınarak yapılmasına çok yardımcı olmuştur (Kaval, 2005: 121).

İç kontrolün asıl amacı yapılan hata ve hileleri önlemek veya bunları ortaya çıkararak işletmeyi oluşabilecek zarardan korumaktır. Ancak iç kontrol sisteminin mükemmel olmasını sağlamak hem maliyetleri artıracaktır hem de pratik olarak imkânsızdır. Bu yüzden işletmelerde iç kontrol sistemi kurulurken bazı faktörlerin göz önünde bulundurulması ve değerlendirilmesi gerekmektedir. Bu değerlendirme sonucunda iç kontrol sistemini kurmaya veya kurulacak sistemlerin organlarını belirlemeye, sistemde görev alacak personeli belirlemek gerekmektedir. (Türedi, 2012: 28) İç kontrol sistemi kurulurken dikkat edilmesi gereken unsurlar risk ve maliyet faktörü olmak üzere iki ana başlıkta incelenecektir.

\section{4. İç Denetim}

İ̧̧letme terimi olarak kontrol, asıl amaçlar gerçekleştirildiği ve bu amaçları gerçekleştirme yolunda sorunlarla karşılaşıldığında, bu sorunları çözmek için önlemlerin alındığından emin olunması olarak ifade edilebilir (Kulak, 2009: 6).

İç denetim, yetersizlikleri göstermek ve iyileştirmelere yönelik tavsiyelerde bulunmak üzere yönetsel kontrol sistemlerinin izlenmesi, sisteme ilişkin üst yönetime rapor sunulması faaliyetidir. (Özeren ve Aral, 2000: 25)

İç denetim, bir kurumun idarecilerinin, sorumlu oldukları süreçlerin hile, hata veya verimli ve tutumlu olmayan uygulamaların meydana gelme olasılığını en aza indirecek şekilde işlediğine dair güvence elde etmesini sağlayan işlevsel bir araçtır. İç denetim, iç kontrol sisteminin etkinliğinin ölçülerek ve değerlendirilerek yönetime sunulan bağımsız bir belirleme hizmetidir (Akyel 2010: 5).

\section{5. İç Denetim ve Hile}

İşletmede kurulan iç denetim sisteminin amaçlarından bir tanesi hileleri önlemektir. İç denetçiler, hilelerin önlenmesine yönelik oluşturulan iç kontrollerin nasıl uygulanacağının yanı sıra kontrol modelinin içeriğini de önerebilir. İşletmelerde yapılan hilelerin başarıya ulaşmasının yolu kontrolleri aşabilmekten geçmektedir. Büyük tutarlı hileler üst düzey yöneticiler tarafından yapılmaktadır. Bunun nedeni üst düzey yöneticilerin işletmede sahip olduğu konumun vermiş olduğu gücü kontrolleri delmekte kullanmaları veya kontrollerin zayıf noktasını bilmeleridir. Bu gibi problemlerin yaşanmaması için iç kontrol sistemi oluşturulurken iç denetçilerin, iç denetimlerini değerlendirme ve tasarlama sürecine katılması sağlanmalıdır. Aslında bazı kuruluşlar, yeni tasarlanan iç denetimlerinin denetim uzmanlarından onay almasını şart koşmaktadır. (Bozkurt, 2011: 418) 


\section{3. ÖRNEK OLAY INCELEMESI}

XYZ Dağıtım Şirketi, yılda 140 milyon adet gönderiyi 900 civarı şubesi ve yaklaşık 14.000 çalışanı ile yerine ulaştıran, sektörün lideri konumundaki bir firmadır. Firmanın 50 kadar e-ticaret sitesi ile gönderi anlaşması bulunmakta ve aylık ortalama 900.000 adet ödemeli gönderiyi teslim etmektedir.

Firmanın A şubesine yapılacak rutin habersiz denetim öncesi, görevli iç denetçi, yapmış olduğu denetim hazırlığında, nakit kullanımı açısından önemli görülen tahsilatlı gönderilerin teslim durumlarını incelemiştir. Yapılan incelemede 500 TL üzeri ve 10 gün üzeri devirde olan 7 adet gönderi riskli olarak değerlendirilmiş olup, yerinde denetimde incelenmek üzere not edilmiştir. İlgili şubesinde yapılan denetimde, riskli olarak belirlenen gönderiler öncelikle devir kontrolünden geçirilmiş, gönderilerin dağıtım için personel B’nin zimmetinde olduğu belirlenmiştir. Sistem üzerinden yapılan kontroller sonucu, ilgili gönderilerin alıcı müşteri bilgilerine ulaşılarak iletişime geçilmiş, hizmet kalitesi memnuniyeti başlığı altında gönderilerini zamanında alıp almadıkları ve personel davranışları hakkında sorular sorulmuştur.

Riskli olarak belirlenen 7 gönderinin de zamanında teslim edildiği ve tahsilatlı gönderi bedellerinin kapıda personele ödendiği ve aldıkları hizmetten memnun oldukları cevapları alınmıştır. Müşterilerden yapılan doğrulama sonucunda, teslim edilen 7 adet gönderinin sistem üzerinden teslim düşülmediği ve tahsilatlı gönderi bedellerinin kasa girişlerinin yapılmadığı tespit edilmiştir.

Personel B ile yapılan görüşmede, direkt hile olayından bahsedilmeyerek, şube içerisindeki personel ilişkileri başlığı altında görüşüleceği bilgisi verilmiştir. Yapılan görüşmede, personel B öncelikle genel olarak bilgiler vermiş ve rutin işleyiş hakkında görüşülmüştür. Personel B'nin kullanmış olduğu pahalı cep telefonu dikkat çekici olarak değerlendirilmiştir.

Teslim edilmemiş olarak zimmetinde görülen 7 adet gönderi hakkında bilgisi sorulduğunda, ilgili gönderilerin teslim edilmediğini belirtmiş, alıcı müşteriler ile yapılan doğrulama neticesinde elde edilen belge ve bilgiler kanıt olarak sunulduğunda ise, tahsilatlı gönderi bedellerini zimmetine geçirdiğini itiraf etmiştir.

Hile vakasını nasıl yaptığının sorgulanması üzerine, elde edilen bilgiler şöyledir. Bahis oyunlarına karşı zafiyetinden dolayı para kaybettiğini ve bu durumun kendisinde baskı oluşturduğunu, ve şube yöneticilerinin devir kontrollerini bizzat kendilerinin fiziki olarak karşılaştırmalı olarak yapmaları gerekirken, bu talimata uymayarak dağıtıcı personele yaptırmalarını bir fırsat olarak görerek, borçlarını kapatmak için hileye başvurduğunu belirtmiştir.

Hile eylemini nasıl gerçekleştirdiği sorulduğunda ise, teslim etmiş olduğu gönderilerin barkodlarının cep telefonu ile fotoğrafını çekerek, akşam kapanış işlemlerinde fotoğraflar üzerinden okutarak devire aldığını belirtmiş, birim yöneticilerinin herhangi bir kontrol yapmamasının kendisine fırsat sunduğunu belirtmiştir. Kullanmış olduğu pahalı cep telefonu ile ilgili bilgi istendiğinde de zimmetine geçirdiği paralar ile lüks harcamalar da yaptığını belirtmiştir. Zimmetine geçirmiş olduğu tutarları bahis oyununda para kazanınca yerine koyacağını belirterek, hile olarak nitelendirilmeyeceğini belirterek, kendini haklı gösterdiği de belirlenmiştir.

Aşağıda sunulan şekil ile incelenen örnek olayda ortaya çıkarılan hilenin, sistemsel akışı ve sonuçları görselleştirilmiştir

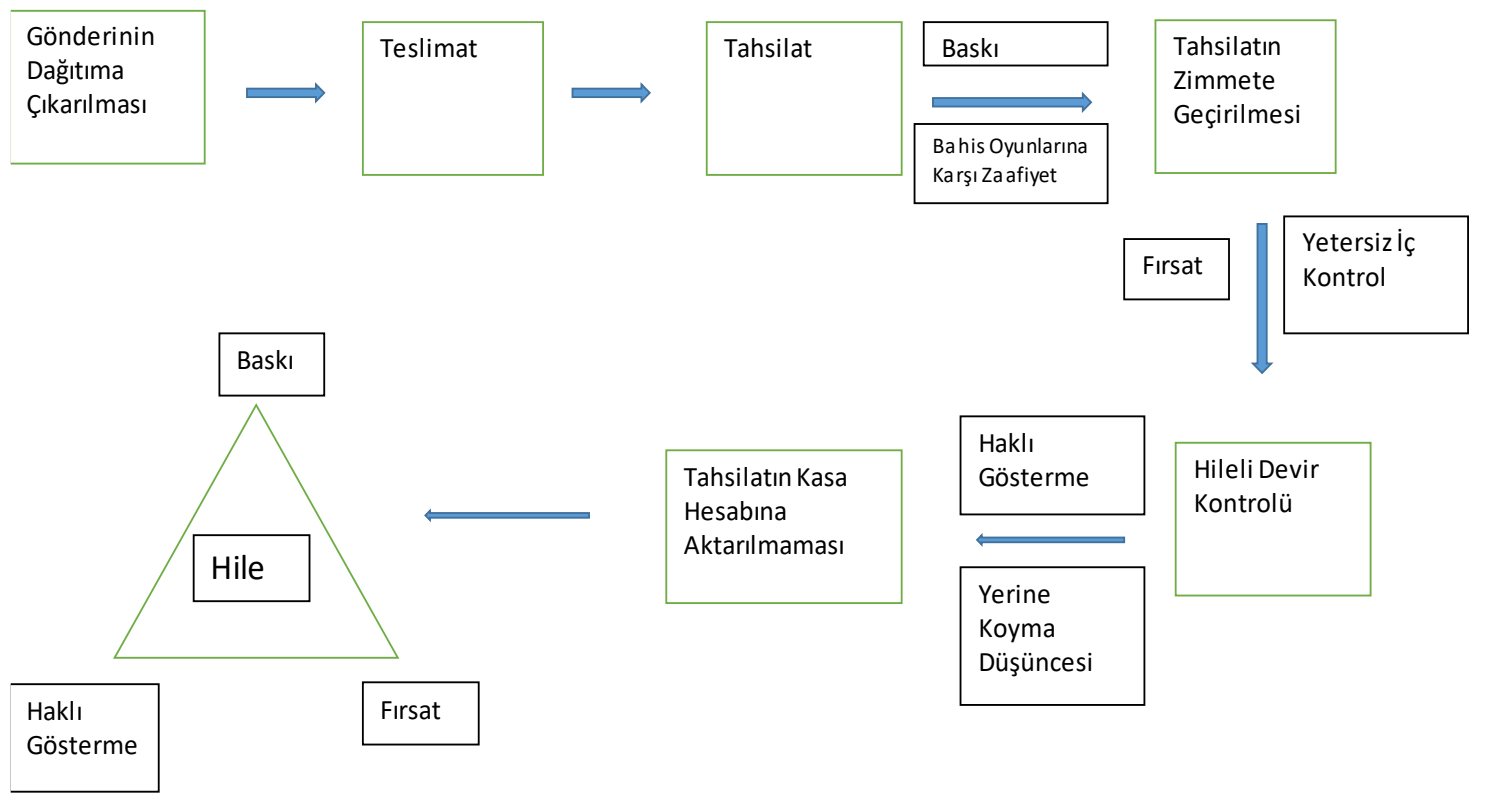


İ̧ denetim ile ortaya çıkarılan bu yolsuzluk ile ortaya konabilecek bulgular;

$\checkmark \quad$ Personel B'nin 7 adet tahsilatlı gönderi ücretinin tahsilatından elde ettiği 5.000 TL'yi zimmetine geçirmesi

$\checkmark$ Personel B hile eylemini gerçekleştirirken, şube yöneticilerin devir kontrol talimatlarına uymamalarından kaynaklı iç kontrol zafiyetini fırsata çevirmesi

$\checkmark \quad$ Gönderileri zimmete alıp dağıııma çıkaran personele akşam işleyişinde deviralma işlemi de yaptııılarak, görevlerin ayrılığı ilkesine aykırı bir işlem yapılması nedeniyle, hile için uygun bir ortam yaratılması.

\section{SONUÇ VE ÖNERILER}

Personel B’nin bahis oyunlarındaki kaybının kendisinde bir baskı oluşturduğu, yönetici uygulamalarından kaynaklı iç kontrol yetersizliklerinin fırsat unsurunu oluşturduğu ve personel B'nin zimmetine geçirdiği paraları yerine koyacağı düşüncesiyle kendini haklı görmesi ilgili hile vakasında hile üçgenin tüm unsurlarının oluştuğunu göstermektedir.

İşletme yöneticilerinin uygulayacakları iç kontroller ile çalışanlara hile yapma fırsatlarını sunmamaları gerekir. Bu nedenle, hile tespitinden önce hilenin gerçekleşmemesi için sistemsel boşlukların giderilmesinin ve önlem alınmasının daha faydalı olacağı önerilmektedir.

\section{KAYNAKÇA}

Adiloğlu, B., (2011), İç Denetim Süreci ve Kontrol Prosedürleri, Türkmen Kitapevi, İstanbul, 3-110.

Akdemir, Ç. (2010). İşletmelerde Hile Riski ve Türk İşletmelerinde Hile Riskinin Ölçülmesi ve Değerlendirilmesi, Yüksek Lisans Tezi, İstanbul: Marmara Üniversitesi Sosyal Bilimler Enstitüsü.

Aksoy, T., (2007), Basel II ve İç Kontrol, Ankara SMMM Odası Yayın No:53, Ankara, 215-334.

Ayşe Ertürk, (2010). İşletmelerde Hata Ve Hileyi Önlemede iç Kontrol Sisteminin Etkililiği, Yüksek Lisans Tezi, i̇stanbul.

Bozkurt, N. (2011). İşletmelerin Kara Deliği Hile Çalışan Hileleri, İstanbul: Alfa Yayınları.

Kaval, H. (2005). Muhasebe Denetimi Uluslararası Finansal Raporlama Standartları Uygulama Örnekleriyle, 2. Basım, Ankara: Gazi Kitapevi.

Kirik, Z. (2007). Muhasebe Hata ve Hileleri Ile Muhasebe Mesleğinde Etik: Afyonkarahisar' da Muhasebeciler Üzerine Bir Araştırma, Yüksek Lisans Tezi, Eskişehir.

Kulak, F. (2009). Merkez Bankalarında iç Kontrol ve İç Denetim: Kavramsal Çerçeve Ve Türkiye Cumhuriyet Merkez Bankası'nda iç Kontrol ve İç Denetim Etkililiği Konusunda Bir Değerlendirme, Marmara Üniversitesi Sosyal Bilimler Enstitüsü, Yayımlanmamış Doktora Tezi, İstanbul

Okay, S. (2011). Muhasebe Hata ve Hilelerinin Meslek Etiği Açısından İrdelenmesi, Karamanoğlu Mehmetbey Üniversitesi Sosyal Bilimler Enstitüsü, Yüksek Lisans Tezi, Karaman.

Terzi, S. (2012). Hileli Finansal Raporlama Önleme ve Tespit IMKB İmalat Sanayiinde Bir Araştırma, İstanbul: Beta Yayınları.

Tüm, K., Memiş, M.Ü., (2012), İç Kontrol, Ulusal ve Uluslararası Düzenlemeler Çerçevesinde Bir Değerlendirme, Karahan Kitapevi, Adana

Türedi, S. (2012). İç Kontrol Sistemi ve Toplam Kalite Yönetimi ilişkisi. Uluslararası Alanya İşletme Fakültesi Dergisi, C:4, S:1.

Uzay, Ş. ve Selimoğlu, S. K. (2007). Türkiye'de Muhasebe Denetimi Alanında Yayınlanan Araştırmalar (1995-2005) ve Seçme Yazılar, İstanbul: isMMO Yayın No:82. 